\title{
Correction to: Tandem affinity purification of AtTERT reveals putative interaction partners of plant telomerase in vivo
}

\author{
Jana Majerská ${ }^{1,2,3} \cdot$ Petra Procházková Schrumpfová $^{2} \cdot$ Ladislav Dokládal $^{1} \cdot$ Šárka Schořová $^{2} \cdot$ Karel Stejskal $^{2}$. \\ Michal Obořil ${ }^{2}$. David Honys ${ }^{4}$. Lucie Kozáková ${ }^{2} \cdot$ Pavla Sováková Polanská $^{2}$ • Eva Sýkorová ${ }^{1}$
}

Published online: 14 February 2018

(C) Springer-Verlag GmbH Austria, part of Springer Nature 2018

Correction to: Protoplasma (2017) 254:1547-1562

https://doi.org/10.1007/s00709-016-1042-3

In the published online version, the affiliations were mixed up. Corrected affiliation section is shown below. Also, the update has also been reflected in the author group section above.

Jana Majerská and Petra Procházková Schrumpfová are both co-authors

The online version of the original article can be found at https://doi.org/ 10.1007/s00709-016-1042-3

Eva Sýkorová

evin@ibp.cz

1 Institute of Biophysics, Academy of Sciences of the Czech Republic, v.v.i, Královopolská 135, CZ-61265 Brno, Czech Republic

2 Central European Institute of Technology and Faculty of Science, Masaryk University, Kotlářská 2, CZ-61137 Brno, Czech Republic

3 Present address: Swiss Institute for Experimental Cancer Research (ISREC), School of Life Sciences, École Polytechnique Fédérale de Lausanne (EPFL), 1015 Lausanne, Switzerland

4 Institute of Experimental Botany, Academy of Sciences of the Czech Republic v.v.i, Rozvojová 263,

CZ-16502 Prague, Czech Republic 